COMETTI, N.N.; MATIAS, G.C.S.; ZONTA, E,; MARY, W.; FERNANDES, M.S. Compostos nitrogenados e açúcares solúveis em tecidos de alface orgânica, hidropônica e convencional. Horticultura Brasileira, Brasília, v.22, n.4, p.748-753, out-dez 2004.

\title{
Compostos nitrogenados e açúcares solúveis em tecidos de alface orgâni- ca, hidropônica e convencional ${ }^{1}$
}

\author{
Nilton Nélio Cometti²; Gean Carlos S. Matias ${ }^{3}$; Everaldo Zonta ${ }^{3}$; Wellington Mary ${ }^{4}$; Manlio S. Fernandes ${ }^{3}$ \\ ${ }^{2}$ Escola Agrotécnica Federal de Colatina, BR 259, km 70, 29709-910 Colatina-ES. nilton@eafcol.gov.br, \\ home:www.niltoncometti.com.br; ${ }^{3}$ UFRRJ, Depto. Solos, BR 465, km 07, 23850-000 Seropédica-RJ; ${ }^{4}$ UFRRJ, Depto. Arquitetura e \\ Urbanismo
}

\section{RESUMO}

O presente trabalho foi realizado na UFRRJ e teve como objetivo verificar as variações de alguns componentes metabólicos nos tecidos da alface. Plantas de alface do tipo crespa, da cultivar Verônica, provenientes de três sistemas de cultivo, orgânico, hidropônico e convencional, foram separadas em oito partes (limbo das folhas basais, medianas e apicais, nervura central das folhas basais, medianas e apicais, caule e raiz). Foram analisados nitrato, $\mathrm{N}$-amino, açúcares livres e distribuição da massa seca nos vários tecidos. Considerando a parte aérea e raízes, os teores encontrados assemelham-se aos da literatura. Porém, quando as análises são realizadas nos tecidos que compõem a parte aérea, há diferenças significativas em todas as variáveis. Isso permite escolher partes da planta para analisar, dependendo do que se deseja observar. Em estudos fisiológicos, principalmente de metabolismo do nitrogênio, a segmentação das partes pode ser fundamental na interpretação dos resultados. $\mathrm{Na}$ análise de nitrato, $\mathrm{N}$-amino e açúcares livres na alface, é recomendada a separação de folhas e caule da parte aérea por terem apresentado grandes diferenças. A alface em cultura hidropônica mostrou teores de nitrato bem superiores aos outros sistemas de cultivo, chegando ao máximo de $1000 \mathrm{mg} \mathrm{kg}^{-1}$ massa fresca do caule, valor esse, entretanto, bem abaixo do máximo permitido pela legislação européia para acúmulo de nitrato em alface. Podese sugerir que o caule da alface funcione como o principal órgão de reserva temporário de compostos nitrogenados livres, principalmente nitrato e N-amino, além de açúcares solúveis. Maiores estudos são necessários para confirmar se o caule teria efeito tampão caso as plantas da alface absorvessem grandes quantidades de nitrogênio na forma nítrica e amoniacal.

Palavras-chave: Lactuca sativa, compartimento, nutrientes na planta, nitrato.

\begin{abstract}
Nitrogen compounds and soluble sugars in tissues of organic, hydroponic, and conventional lettuce

The distribution of some physiologic metabolites was evaluated in lettuce plants. Crest leaf lettuce plants were grown in the organic, hydroponic, and conventional system. Plants from each systems were split in eight parts (old, medium, and new leaf limbos, old, medium, and new main leaf veins, stem and root). Analyses of nitrate, amino$\mathrm{N}$, soluble sugars, and dry mass partition were accomplished throughout the parts. In general, considering the aerial part and roots, the contents resemble literature reports. However, when the analyses are accomplished in the different plant parts that compose the shoot, there are significant differences among parts in all analyzed metabolites. This allows a better choice of which part of the plant to analyze, depending on what one wants to observe. During physiologic studies of nitrogen metabolism, the separation of parts may be fundamental in the interpretation of the results. Nitrate, amino-N and free sugars showed great differences between shoot parts and stem. Stems appear to accumulate their maximum contents. The hydroponic lettuce showed nitrate contents greater than any other lettuces, reaching a maximum of $1,000 \mathrm{mg} \mathrm{kg}^{-1}$ of fresh mass in stems. Therefore, this amount is well below the maximum allowed by the European legislation for lettuce nitrate content. The results suggest that the lettuce stem works as the main accumulator of free nitrogen compounds, specially nitrate and amino- $\mathrm{N}$, besides soluble sugars. Further studies are necessary to confirm if lettuce stems would have buffer function in case of large amounts of nitrogen uptake.
\end{abstract}

Keywords: Lactuca sativa, compartment, nitrate, plant nutrient.

\section{(Recebido para publicação em 18 de fevereiro de 2004 e aceito em 13 de setembro de 2004)}

\begin{abstract}
$\mathrm{A}$ alface (Latuca sativa L.) é cultivada em todo o território nacional e compõe uma parcela importante dos vegetais da dieta da população, tanto pelo sabor e qualidade nutritiva, quanto pelo baixo custo. Seu consumo, normalmente é feito in natura (Faquin et al., 1996).

Variáveis de grande significância fisiológica, tais como acúmulo de $\mathrm{NO}_{3}^{-}$ (nitrato), $\mathrm{N}$-amino e açúcares solúveis, são fundamentais para a pesquisa em
\end{abstract}

nutrição da planta, e em especial da nutrição nitrogenada. Em algumas culturas, tem-se observado grandes variações nesses compostos ao longo dos diferentes tecidos da planta, dificultando a interpretação de resultados, quando as análises são segmentadas, limitando-se a algumas partes, tais como folhas e raízes. Por outro lado, análises da planta como um todo ou de parte aérea e raízes separadamente, podem levar a resultados também duvidosos, já que a distribuição de algumas variáveis fisiológicas não é levada em conta. Tem sido demonstrado que algumas plantas utilizam partes da sua estrutura para acumular nitrogênio solúvel na forma de nitrato e $\mathrm{N}$-amino, como por exemplo o caule da alface (Cometti, 2000), rizoma e raízes em Paspalum notatum (Bendix et al., 1982).

\footnotetext{
${ }^{1}$ Parte da tese de doutorado em Agronomia-ciência do solo do primeiro autor.
} 
O nitrato acumulado no tecido da alface tem recebido atenção especial nos últimos anos, pois se ingerido pelos animais a partir dos alimentos pode ser reduzido a nitrito $\left(\mathrm{NO}_{2}^{-}\right)$no trato digestivo, e ao chegar à corrente sangüínea oxidando o ferro $\left(\mathrm{Fe}^{2+} \rightarrow \mathrm{Fe}^{3+}\right)$ da hemoglobina produzindo metahemoglobina. A metahemoglobina torna-se estável e inativa, tornando-se incapaz de transportar oxigênio $\left(\mathrm{O}_{2}\right)$ para a respiração celular, acarretando a doença conhecida como metahemoglobinemia, ou doença do "sangue azul” (Wright e Davison, 1964). De outro lado, o nitrito pode combinar-se com aminas formando "nitrosaminas" que se caracterizam por serem cancerígenas e mutagênicas (Maynard et al., 1976). Entretanto, Leifert et al. (1999) mostram que experimentos tentando ligar o aparecimento de câncer à dieta rica em nitratos contêm resultados contraditórios. Trabalhos mais recentes mostram que o nitrato pode ser benéfico à saúde em doses comumente ingeridas nos alimentos (Golden e Leifert, 1999; Boink et al.,2001; Archer, 2002).

Os níveis de nitrato em alface considerados aceitáveis para o consumo humano variam bastante. Na Europa, vários países têm estabelecido limites máximos tolerados de 3500 a $4500 \mathrm{mg}$ de $\mathrm{NO}_{3}^{-} \mathrm{kg}^{-1}$ de massa fresca para cultivo de inverno e $2500 \mathrm{mg}$ de $\mathrm{NO}_{3} \mathrm{~kg}^{-1}$ de massa fresca para cultivos de verão (Van Der Boon et al., 1990).

Do ponto de vista metabólico, o acúmulo de $\mathrm{NO}_{3}^{-}$nos tecidos dá-se pelo alto influxo do ânion sem que haja disponibilidade de poder redutor proveniente do $\mathrm{NADH}^{+}$para a redução no $\mathrm{NO}_{3}^{-}$a $\mathrm{NO}_{2}^{-}$pela enzima Nitrato Redutase (Campbell, 1999), e da Ferredoxina para a redução, pela Nitrito Redutase, do $\mathrm{NO}_{2}^{-}$a $\mathrm{NH}_{4}^{+}$, cuja assimilação também depende da disponibilidade de esqueletos de carbono (açúcares) para a formação de aminoácidos. Como a Ferredoxina é reduzida em nível de cloroplastos a partir de elétrons capturados pelo Fotossistema I, a planta no escuro tende a apresentar um déficit de poder redutor, podendo acumular nitrito, que por "feedback" inibe a ação da nitrato redutase, acumulando assim o $\mathrm{NO}_{3}{ }^{-}$absorvido. Para que isso ocorra, é necessário que as outras variáveis como temperatura e disponibilidade de
ATP sejam favoráveis à absorção do $\mathrm{NO}_{3}^{-}$(Fernandes, 1983). As variações cíclicas diurnas no influxo de $\mathrm{NO}_{3}^{-} \mathrm{e}$ $\mathrm{NH}_{4}^{+}$também promovem grandes variações no acúmulo tanto de $\mathrm{N}-\mathrm{NO}_{3}$ - quanto $\mathrm{N}$-amino livres, principalmente nas raízes das planta (Delhon et al., 1995).

Alguns manuais de análises de nutrientes nos tecidos de plantas recomendam a coleta de partes específicas da alface tais como a folha madura mais jovem do topo da planta (Kalra, 1998) e folhas recém-desenvolvidas (Embrapa, 1999). A distribuição precisa dos nutrientes, bem como a compartimentalização dos elementos relacionados ao metabolismo do nitrogênio, devem ser investigadas para melhorar tanto a compreensão dos resultados de análises quanto a amostragem do material.

O objetivo do presente trabalho foi avaliar a distribuição de $\mathrm{NO}_{3}^{-}, \mathrm{N}$-amino e açúcares livres nos diferentes tecidos da alface sob cultivo convencional, orgânico e hidropônico.

\section{MATERIAL E MÉTODOS}

Plantas da alface da variedade crespa (Verônica) foram colhidas em três diferentes sistemas de cultivo comercial de produtores vizinhos à UFRRJ (sistemas orgânico, convencional e hidropônico). No sistema orgânico, a adubação restringiu-se apenas à utilização de adubo orgânico, principalmente esterco bovino e cama de aves, na dosagem de $20 \mathrm{t} \mathrm{ha}^{-1}$. No sistema convencional, além do esterco bovino, foram utilizados $300 \mathrm{~kg} \mathrm{ha}^{-1}$ da fórmula 4-14-8 de NPK no plantio. O sistema hidropônico utilizou a solução nutritiva preconizada por Furlani (1997), com condutividade de $1,0 \mathrm{mS} \mathrm{cm} \mathrm{cm}^{-1}$ (metade da força iônica). Em cada sistema de cultivo foram coletadas 4 plantas, no horário de 7:00 h, no mês de setembro de 2000, sem ocorrência de tempo encoberto nos últimos 3 dias antes da coleta, e com temperaturas amenas durante o período. As temperaturas médias foram de 20,5 e $20,7^{\circ} \mathrm{C}$, com amplitude de 11,6 e $8,3^{\circ} \mathrm{C}$, as umidades relativas médias foram 66 e $74 \%$ e as precipitações mensais acumuladas foram 56,7 e $136,7 \mathrm{~mm}$, nos meses de agosto e setembro, respectivamente (base de dados agroclimatológicos da Estação Experimental de Itaguaí/PESAGRO-Rio Latitude: $22^{\circ} 45^{\prime} \mathrm{S}$ - Longitude: $43^{\circ} 41^{\prime} \mathrm{W}$ - Altitude: $33 \mathrm{~m}$ ). Todas as plantas coletadas estavam em idade adulta e prontas para a comercialização. As plantas hidropônicas tinham idade de 45 dias após a semeadura (DAS), e as do cultivo convencional e orgânico, em torno de 70 DAS.

\section{Preparo das amostras}

As plantas foram imediatamente levadas ao laboratório e separadas em 8 partes. Inicialmente, as folhas foram destacadas do caule e distribuídas em três partes: folhas do terço basal, folhas do terço médio e folhas do terço apical. Delas foram separados o limbo foliar e a nervura central. Finalmente, foram separados o caule e as raízes. A seguir são dadas as convenções para as oito partes: $\mathrm{LB}=$ limbo das folhas basais; $\mathrm{LM}=$ limbo das folhas medianas; $\mathrm{LA}=$ limbo das folhas apicais; $\mathrm{NB}=$ nervura central das folhas basais; $\mathrm{NM}=$ nervura central das folhas medianas; $\mathrm{NA}=$ nervura central das folhas apicais; $\mathrm{C}=$ caule; $\mathrm{R}=$ raízes; $\mathrm{PA}=$ média ponderada de todos os tecidos da parte aérea, incluindo caule. Após a separação das partes, as mesmas foram pesadas, cortadas em pedaços (picadas) e homogeneizadas para retirada de uma alíquota de um grama de tecido fresco. Este foi acondicionado em vidro âmbar, com 20 ml de álcool etílico a $80 \%$ para extração de $\mathrm{NO}_{3}^{-}, \mathrm{NH}_{4}^{+}, \mathrm{N}$-amino e açúcares solúveis (Fernandes, 1974).

\section{Extração alcoólica e separação}

As amostras de $1 \mathrm{~g}$ em etanol $80 \%$ foram trituradas em almofariz por $3 \mathrm{mi}-$ nutos, filtradas em quatro camadas de gaze clínica e papel de filtro de filtragem rápida. $\mathrm{O}$ filtrado foi transferido para funil de separação onde foi adicionado igual volume de clorofórmio, agitado suavemente e deixado em repouso por $40 \mathrm{mi}-$ nutos para a completa separação. A fração apolar foi descartada e a polar foi recolhida, completada a $25 \mathrm{ml}$ com etanol a $80 \%$ e guardada em geladeira para as determinações (Fernandes, 1974).

\section{Análises de NO3-, NH4+, N-amino e açúcares solúveis}

Nitrato foi determinado colorimetricamente por técnica adaptada de Cataldo et al. (1975), a partir da 


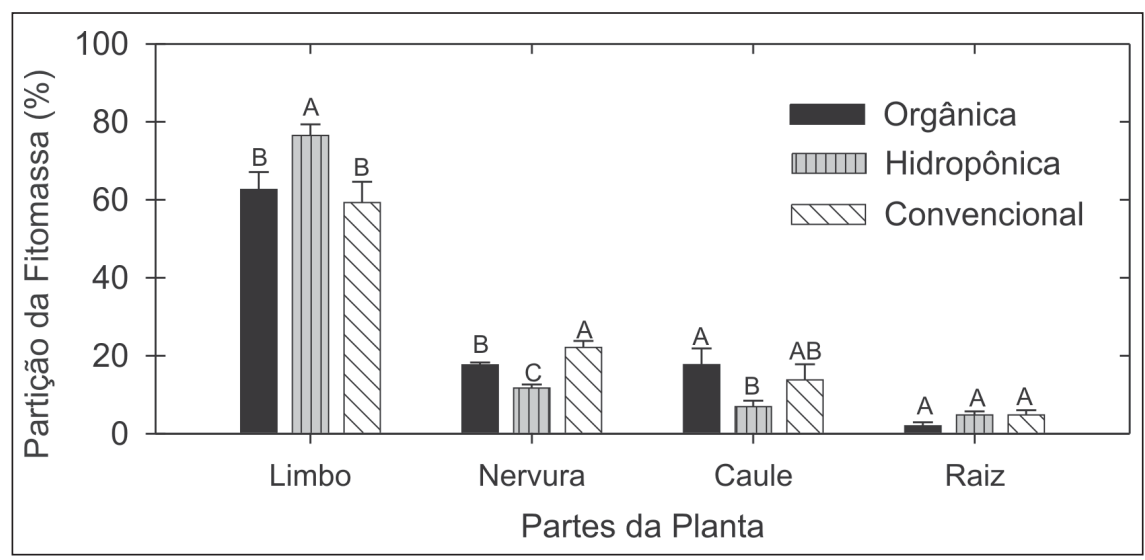

Figura 1. Partição da fitomassa das alfaces orgânica, hidropônica e convencional. Limbo e nervura pertencem às folhas. Cada barra representa a média de quatro repetições e as barras de erro indicam desvio padrão. Letras sobre as barras comparam sistemas de cultivo pelo teste de Tukey $(\mathrm{p}=5 \%)$. Seropédica (RJ), UFRRJ, 2004.

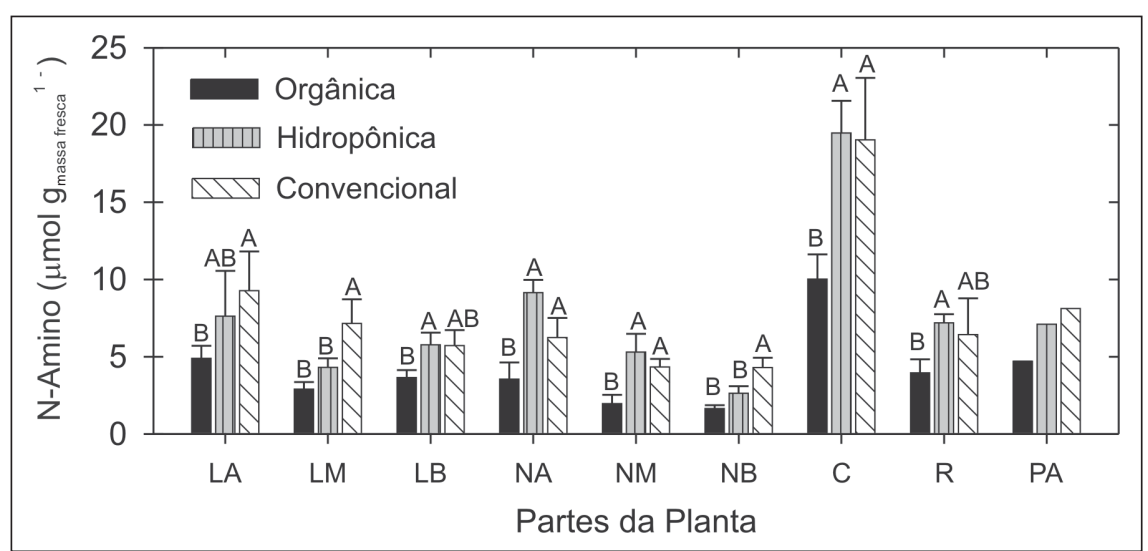

Figura 2. Teores de N-amino nos vários tecidos das alfaces orgânica, hidropônica e convencional. LA: limbo das folhas apicais; LM: limbo das folhas medianas; LB: limbo das folhas basais; NA: nervura central das folhas apicais; NM: nervura central das folhas medianas; NB: nervura central das folhas basais; C: caule; R: raízes; PA: parte aérea. Cada barra representa a média de quatro repetições e as barras de erro indicam desvio padrão. Letras sobre as barras comparam sistemas de cultivo pelo teste de Tukey $(\mathrm{p}=5 \%)$. Seropédica (RJ), UFRRJ, 2004.

nitração do ácido salicílico e leitura em espectrofotômetro a $410 \mathrm{~nm}$. A determinação de $\mathrm{N}$-amino com ninidrina foi feita segundo método descrito por Yemm e Cocking (1955), e leitura em espectrofotômetro a $570 \mathrm{~nm}$. Finalmente, os açúcares solúveis foram determinados pelo método da antrona adaptado de Yemm e Willis (1954) e a leitura feita em espectrofotômetro a $620 \mathrm{~nm}$. Para as análises, foi utilizado um espectrofotômetro Shimadzu UV1200.

$\mathrm{Na}$ confecção dos gráficos foram utilizados os programas de computação Microsoft Excel® e SigmaPlot ${ }^{\circledR}$ (SPSS Science, Chicago, IL), e nas análises estatísticas, o programa SigmaStat ${ }^{\circledR}$. O delineamento utilizado foi $o$

inteiramento casualizado e os dados ram submetidos à análise de variância e teste de médias (Tukey a 5\% de significância).

\section{RESULTADOS E DISCUSSÃO}

\section{Distribuição da Massa Seca na} Planta

A maior parte da massa seca encontra-se nos limbos foliares, variando de $59 \%$ na alface convencional a $76,4 \%$ na hidropônica. Por outro lado, a menor fração de massa seca encontra-se nas raízes, variando de $2 \%$ na orgânica a $4,9 \%$ na convencional. A fração de massa seca contida nas nervuras das folhas e na convencional, respectivamente, enquanto no caule a hidropônica chega a $7 \%$ e a orgânica a $18 \%$ da massa seca total da planta (Figura 1). Dados apresentados por Faquin et al. (1996) para alface hidropônica da cultivar Verônica, em ponto comercial, mostram valores de partição da massa seca de $81,1 \%$ para as folhas, $5,8 \%$ para o caule e $13,04 \%$ para as raízes; ou seja, um percentual maior de massa alocada às raízes. Em termos gerais, a alface hidropônica investe menor quantidade de massa seca na formação do caule e das nervuras centrais das folhas, melhorando a distribuição no limbo foliar. Essa maior relação limbo foliar: nervuras+caule é interessante do ponto de vista comercial e nutricional. Em relação ao sistema radicular, esperar-se-ia um maior investimento de carbono em sistema radicular pelas plantas cultivadas em solo, alfaces orgânica e convencional, do que nas plantas cultivadas em solução nutritiva. Isso não foi observado possivelmente pela dificuldade de se recuperar todas as raízes das plantas cultivadas no solo e, adicionalmente, pela recuperação de todo o sistema radicular das plantas cultivadas em hidroponia. Apesar da alocação de massa nos tecidos da planta estar ligada à espécie e cultivar, o rápido crescimento da planta em hidroponia aliado à farta disponibilidade de nutrientes na solução nutritiva e relativamente menor estresse hídrico permitem a produção de plantas menos fibrosas, com folhas mais suculentas, e, portanto com menor consumo de carbono na produção de paredes mais rígidas, com mais celulose ou lignina. varia de 12 a $22 \%$ na alface hidropônica

\section{$\mathrm{N}$-amino, açúcares solúveis, $\mathrm{NO}_{3}$ - e $\mathrm{NH}_{4}^{+}$}

$\mathrm{O}$ acúmulo de $\mathrm{N}$-amino na alface sob os três sistemas de cultivo mostra a mesma tendência. Os valores mais elevados foram encontrados dos caules, variando de $10 \mu \mathrm{mol} / \mathrm{g}$ de massa fresca na alface orgânica a $19,5 \mu \mathrm{mol} / \mathrm{g}$ de massa fresca na hidropônica. Os menores teores foram detectados nas nervuras das folhas basais e medianas, variando de 1,6 a 4,3 $\mu \mathrm{mol} / \mathrm{g}$ de massa fresca no orgânico e no convencional, respectivamente (Figura 2). Enquanto as alfaces orgânicas e convencionais tendem a acumular mais $\mathrm{N}$-amino no limbo foliar e no caule, a hidropônica tende a acumu- 
lar mais $\mathrm{N}$-amino nas nervuras das folhas apicais e no caule. Os valores de $\mathrm{N}$-amino na alface orgânica geralmente foram menores do que na convencional e na hidropônica nos tecidos ao longo da planta (Figura 2). As diferenças mais marcantes são observadas entre o caule e todos os outros tecidos, indicando haver um acúmulo de 2 a 4 vezes maior no caule do que nos outros tecidos da alface. Teores de $\mathrm{N}$-amino elevados, normalmente indicam situação de estresse nutricional ou ambiental para as plantas (Fernandes, 1983; Fernandes e Rossiello, 1995). Em alface, Pereira et al. (1989) encontraram valores de $\mathrm{N}$-amino variando de 9 a 16 $\mu$ mol g-1 de massa fresca, não mostrando correlação com excesso de $\mathrm{NH}_{4}^{+}$no solo. Dos resultados encontrados aqui, apenas os teores de $\mathrm{N}$-amino do caule ultrapassam $10 \mu \mathrm{mol} \mathrm{g}{ }^{-1}$ de massa fresca. As colunas referentes a PA (parte aérea), no entanto, mostram valores médios da parte aérea que se situam numa faixa bem abaixo dos encontrados no caule. Isso pode indicar que algumas análises realizadas com a parte aérea como um todo podem "mascarar" a presença de $\mathrm{N}$-amino acumulado em compartimentos dentro da planta, como é o caso do caule.

A Figura 3 mostra os teores de açúcares solúveis totais nos vários tecidos da alface nos três tipos de cultura, com base na equivalência em glicose. No geral, esses teores de açúcares solúveis nas alfaces orgânicas e convencionais seguem a mesma tendência, acumulando em maior quantidade nos caules $\left(13,7 \mathrm{mg} \mathrm{kg}^{-1}\right.$ massa fresca no caule da alface convencional), decrescendo das nervuras e das folhas apicais para as basais. Os menores teores foram encontrados nos limbos e nervuras das folhas basais. Já a alface hidropônica apresenta altos teores de açúcares nas folhas basais (15,4 mg kg-1 de massa fresca), e baixos teores nas raízes $\left(2,33 \mathrm{mg} \mathrm{kg}^{-1}\right.$ de massa fresca). É possível que as folhas basais ainda estejam funcionando como principal fonte de fotossintatos, visto que as plantas apresentavam-se fisiologicamente jovens no momento da colheita. O baixo teor de açúcares solúveis nas raízes da alface hidropônica pode ser resultado da nutrição parcial-

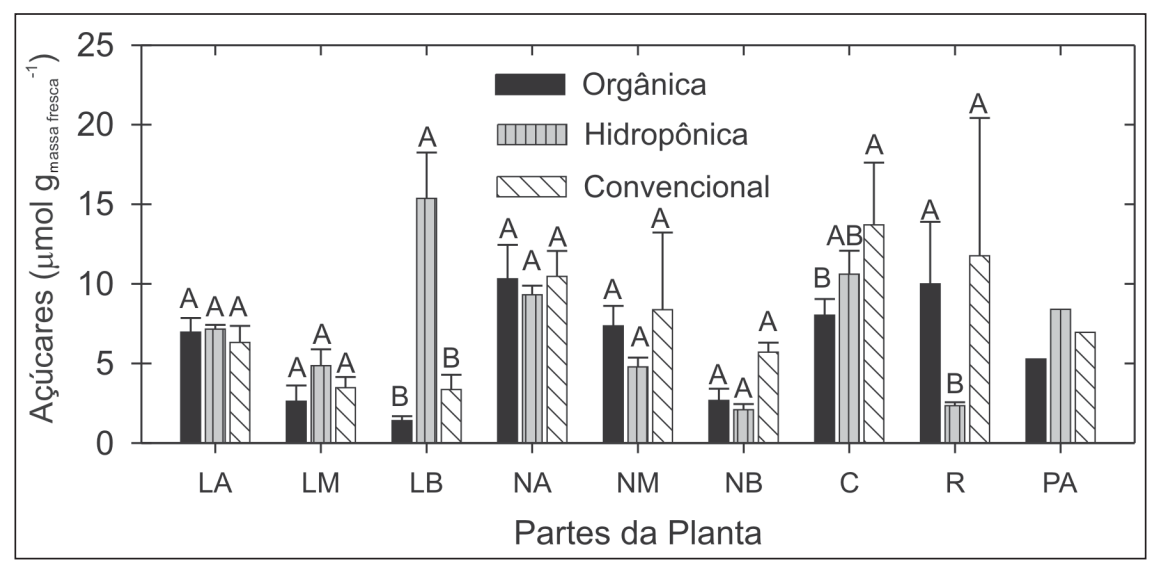

Figura 3. Teores de açúcares solúveis nos vários tecidos das alfaces orgânica, hidropônica e convencional. LA: limbo das folhas apicais; LM: limbo das folhas medianas; LB: limbo das folhas basais; NA: nervura central das folhas apicais; NM: nervura central das folhas medianas; NB: nervura central das folhas basais; $\mathrm{C}$ : caule; R: raízes; PA: parte aérea. Cada barra representa a média de quatro repetições e as barras de erro indicam desvio padrão. Letras sobre as barras comparam sistemas de cultivo pelo de Tukey $(p=5 \%)$. Seropédica $(\mathrm{RJ})$, UFRRJ, 2004.

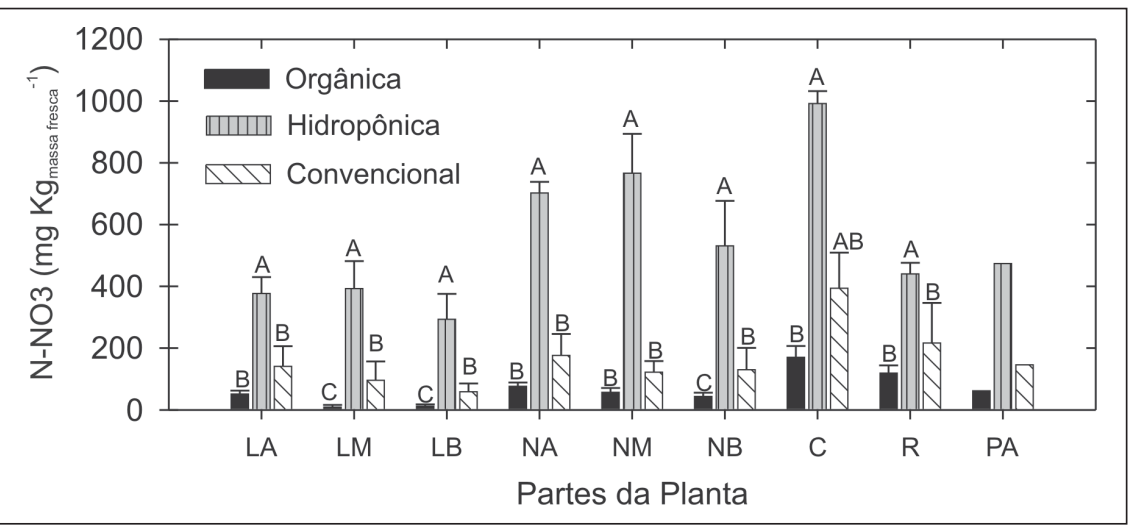

Figura 4. Teores de nitrato nos vários tecidos das alfaces orgânica, hidropônica e convencional. LA: limbo das folhas apicais; LM: limbo das folhas medianas; LB: limbo das folhas basais; NA: nervura central das folhas apicais; NM: nervura central das folhas medianas; NB: nervura central das folhas basais; $\mathrm{C}$ : caule; R: raízes; PA: parte aérea. Cada barra representa a média de quatro repetições e as barras de erro indicam desvio padrão. Letras sobre as barras comparam sistemas de cultivo pelo teste de Tukey $(\mathrm{p}=5 \%)$. Seropédica (RJ), UFRRJ, 2004.

mente amoniacal $(12,5 \%)$ da composição da solução nutritiva (Furlani, 1997). O amônio absorvido deve ser imediatamente incorporado ainda nas raízes, aumentando a demanda por fotossintatos. Além disso, o alto teor de nitrato em toda a planta (Figura Figura 4), além de poder redutor, demanda esqueletos de carbono oriundos da fotossíntese para sua redução e assimilação. Resultados de Fernandes (1990) indicam uma tendência à redução nos teores de açúcares solúveis da parte aérea em plantas de arroz em situação de alta disponibilidade de $\mathrm{NO}_{3}{ }^{-}$. Muitas plantas cultivadas, tais como folhosas, possuem a tendên- cia a reduzir grande parte do nitrato na parte aérea (Marschner, 1995).

Em geral, os maiores acúmulos de nitrato foram observados nos caules para os três tipos de cultura, enquanto que os menores acúmulos foram observados nos limbos das folhas basais. O teor médio de $\mathrm{N}^{-\mathrm{NO}_{3}}{ }_{3}^{-}$na parte aérea (PA) das alfaces sob cultivo orgânico e convencional foram 61,8 e $146 \mathrm{mg} \mathrm{kg}^{-1}$ massa fresca, respectivamente (Figura 4). Esses valores encontram-se dentro do normal, e abaixo do encontrado por Pereira et al. (1989), cujos resultados mostram que os teores de nitrato em alface da variedade Aurélia, cultivada com 
adubação mineral, estiveram na faixa de 108 a $168 \mathrm{mg} \mathrm{kg}^{-1}$ de massa fresca, enquanto a alface cultivada com cama de galinha chegou a $303 \mathrm{mg} \mathrm{kg}^{-1}$. Nesse mesmo experimento, as plantas de alface testemunha acumularam apenas 68,7 $\mathrm{mg} \mathrm{kg}^{-1}$, o que indica a alta variabilidade no acúmulo de nitrato no tecido vegetal frente à disponibilidade do nutriente. Krohn et al. (2003) encontraram maiores teores de nitrato nas folhas novas em relação às folhas maduras, porém o mesmo não foi observado no presente trabalho.

O teor de nitrato mais elevado, no caule, chegou a $992 \mathrm{mg} \mathrm{kg}^{-1}$ massa fresca. Os teores médios de nitrato da parte aérea (PA), no entanto, não passaram de $473 \mathrm{mg} \mathrm{kg}^{-1}$. Nos limbos foliares, os teores estiveram sempre abaixo desse valor, chegando a $393 \mathrm{mg} \mathrm{kg}^{-1}$ no limbo das folhas medianas (LM). Valores semelhantes foram obtidos por Faquin $e t$ al. (1996), onde plantas da alface da cultivar Verônica cultivadas hidroponicamente e colhidas às $6: 00 \mathrm{~h}$ apresentaram 406,2 $\mathrm{mg} \mathrm{N}-\mathrm{NO}_{3}{ }^{-} \mathrm{kg}^{-1}$ de folhas frescas. Outro trabalho, realizado por Ruschel et al. (1998) mostrou que mesmo com altas doses de $\mathrm{NO}_{3}^{-}$na solução nutritiva, a alface hidropônica tanto da cultivar Marisa quanto Vera, ambas crespas, não apresentaram mais do que $340 \mathrm{mg} \mathrm{N}-\mathrm{NO}_{3}{ }^{-} \mathrm{kg}^{-1}$ massa fresca da parte aérea. $\mathrm{O}$ acúmulo de nitrato em órgãos específicos das plantas foi observado por Bendix et al. (1982) e Fernandes et al. (1985), onde raízes e rizomas de Paspalum notatum têm efeito tampão, acumulando o excesso de nitrato para evitar que a absorção de $\mathrm{N}$ em excesso possa afetar o crescimento da parte aérea. Da mesma forma, o caule da alface poderia amenizar grandes acúmulos de $\mathrm{NO}_{3}^{-}$nas folhas, o que necessita maiores estudos para que seja confirmado. Mesmo um teor mais alto de nitrato no tecido, como o encontrado no caule (C) está aquém dos limites máximos permitidos na Europa, 2500 $\mathrm{mg} \mathrm{kg}^{-1}$ de massa fresca para cultivos de verão (Van Der Boon et al., 1990). A maioria dos trabalhos tem tomado a parte aérea inteira da planta para fins de análise de nitrato no tecido. A Figura 4 mostra que o valor médio (PA) situa-se acima dos valores encontrados nos limbos foliares devido ao maior acúmulo nas nervuras centrais das folhas, e no caule (C). Portanto, seria mais razoável destacar as folhas para determinar o teor de nitrato na parte aérea da alface para fins comerciais, visto que o valor mais alto do teor de nitrato nas nervuras das folhas é compensado pelas menores massas frescas das mesmas (Figura 1). Além de o caule apresentar um alto teor de nitrato, sua massa fresca representa quase o mesmo que a soma das nervuras foliares. Adicionalmente, para fins de nutrição humana, utilizamse apenas as folhas, de tal forma que o caule, apesar da alta concentração de nitrato, não representa fator de risco para a saúde. Em termos nutricionais, considerando que um ser humano de $70 \mathrm{~kg}$ em geral não consome mais do que $50 \mathrm{~g}$ de massa fresca da alface por dia, e que o limite para ingestão diária aceitável é de 3,6 mg N-NO - por $\mathrm{kg}$ de peso vivo (Ruschel et al., 1998), a alface deveria conter mais do que $5000 \mathrm{mg} \mathrm{N}-\mathrm{NO}_{3}$ - por $\mathrm{kg}$ de massa fresca para ultrapassar esse limite. Face às condições de elevada disponibilidade de luz e temperatura, seria muito improvável encontrar tais níveis nas condições de clima tropical.

Entre os sistemas de cultivo, a análise estatística indica a superioridade dos teores de nitrato em todos os tecidos da alface hidropônica em relação as outras duas. Teores mais elevados de nitrato nos tecidos da alface hidropônica são esperados devido a maior disponibilidade do nutriente na solução nutritiva. Devido a essa maior disponibilidade, as plantas hidropônicas apresentaram, juntamente com as plantas do cultivo convencional, maiores teores de $\mathrm{N}$-amino (Figura 3), indicando maior taxa de assimilação, aparentemente sem qualquer relação com a disponibilidade de açúcares solúveis nos tecidos que mantiveram-se semelhantes entre plantas dos três cultivos. Esse fato mostra que os níveis de $\mathrm{N}$-amino podem subir não apenas em situações de estresse fisiológico, como abordado por Fernandes (1983), mas também em condições de elevado fluxo de nitrato nos tecidos.

Pode-se concluir que as folhas medianas representam melhor o teor de compostos nitrogenados livres e de açúcares solúveis da parte aérea da alface do que qualquer outro tecido. Em estudos fisiológicos, principalmente em se tratando de metabolismo do nitrogênio, a segmentação das partes pode ser fundamental na interpretação dos resultados. Pode-se sugerir, também que o caule da alface funcione como o principal órgão de reserva temporário de compostos nitrogenados livres, principalmente nitrato, $\mathrm{N}$-amino, além de açúcares solúveis. Maiores estudos são necessários para confirmar se o caule teria efeito tampão caso as plantas da alface absorvessem grandes quantidades de nitrogênio na forma nítrica e amoniacal. Em geral, os tecidos da alface hidropônica apresentaram teores de nitrato maiores do que as alfaces orgânica e convencional, enquanto a alface orgânica apresentou menores teores de $\mathrm{N}$-amino, quando comparada aos outros dois sistemas de cultivo.

\section{LITERATURA CITADA}

ARCHER, D.L. Evidence that ingested nitrate and nitrite are beneficial to health. Journal of Food Protection, v.65, n.5, p.872-875, 2002.

BENDIX, M.E.S.; FERNANDES, M.S.; ROSSIELLO, R.O.P. Aspectos de la nutrición nitrogenada de Paspalum notatum Flügge, en respuesta a fuentes de nitrogeno e inhibicion de nitrificacion. Turrialba, v.32, n.1, p.33-41, 1982. BOINK, A.; SPEIJERS, G.; RAHN, C.; FINK, M. Health effects of nitrates and nitrites, a review. Acta Horticulturae, n.563, p.29-36, 2001.

CAMPBELL, W.H.M.J. Nitrate reductase structure, function and regulation. Ann. Rev. Plant Physiol. Plant Mol. Biol., v.50, p.227-303, 1999. CATALDO, D.A.; HAROON, M.; SCHRADER, L.E.; YOUNGS, V.L. Rapid colorimetric determination of nitrate in plant tissue by nitration of salicylic acid. Commun. in Soil Sci. and Pant Anal., New York, v.6, n.1, p.71-80, 1975.

COMETTI, N.N.; FERNANDES, M.S.; MATIAS, G.C.S. Teores de N-amino livre, açúcares solúveis, nitrato e N-protéico nas várias partes da alface. In: FERTBIO2000, Santa Maria, 2000. Anais... Santa Maria: Sociedade Brasileira de Ciência do Solo, 2000. CD-Rom.

DELHON, P.; GOJON, A.; TILLARD, P.; PASSAMA, L. Diurnal regulation of $\mathrm{NO}_{3}^{-}$uptake in soybean plants. I. Changes in $\mathrm{NO}_{3}^{-}$influx, efflux, and $\mathrm{N}$ utilization in the plant during the day/night cycle. Journal of Experimental Botany, Oxford, v.46, n.291, p.1585-1594, 1995.

EMBRAPA - Embrapa Solos, Embrapa Informática Agropecuária. Manual de Análises Químicas de Solos, Plantas e Fertilizantes. Brasília (DF), Embrapa Comunicação para Transferência de Tecnologia, 1999. 370 p.

FAQUIN, V.; FURTINI NETO, A.E.; VILELA, L.A.A. Produção de alface em hidroponia. Lavras: UFLA, 1996. 50 p. 
FERNANDES, M.S. Effects of light and temperature on the nitrogen metabolism of tropical rice. 1974. (Tese doutorado) Michigan State University, Michigan.

FERNANDES, M.S. N-carriers, light and temperature influences on the free amino acid pool composition of rice plants. Turrialba, v.33, n.3, p.297-301, 1983.

FERNANDES, M.S. Efeitos de fontes e níveis de nitrogênio sobre a absorção e assimilação de N em arroz. Rev. Bras. Fisiol. Vegetal, v.2, n.1, p.16, 1990.

FERNANDES, M.S. Effects of environmental stress on the relationship of free amino- $\mathrm{N}$ to fresh weight of rice plants. Journal of Plant Nutrition, New York, v.14, n.11, p.1151-1164, 1991.

FERNANDES, M.S.; ROSSIELLO, R.O.P. Mineral nitrogen in plant physiology and plan nutrition. Critical Reviews in Plant Sciences, Boca Raton, v.14, n.2, p.111-148, 1995.

FERNANDES, M.S.; ROSSIELLO, R.O.P.; BENDIX, M.E.S. Effects of N-Source, light intensity and temperature on nitrogen metabolism of bahiagrass. J. Plant Nutrition, v.8, n.10, p.945963, 1985.

FURLANI, P.R. Instruções para o cultivo de hortaliças de folhas pela técnica de hidroponia-NFT. Campinas: Instituto Agronômico, 1997. 30 p. (Boletim técnico, 168).
GOLDEN, M.; LEIFERT, C. Potential risks and benefits of dietary nitrate. In: Wilson, W.S., Ball, A.S. and Hinton, R.H.(Eds.). Managing Risks of Nitrates to Humans and the Environment. New York: Springer, 1999. cap. 19, p.269-280.

KALRA, Y.P. (Ed.) Handbook of reference methods for plant analysis. Boca Raton, FL: CRC Press, 1998. 300 p.

KROHN, N.G.; MISSIO, R.F.; ORTOLAN, M.L.; BURIN, A.; STEINMACHER, D.A.; LOPES M.C. Teores de nitrato em folhas de alface em função do horário de coleta e do tipo de folha amostrada. Horticultura Brasileira, Brasília, v.21, n.2, p.216-219, abril/junho 2003.

LEIFERT, C.; FITE, A.;Li, H.; GOLDEN, M.; MOWET, A.; FRAZER, A. Human health effects of nitrate. In: IFA AGRICULTURAL CONFERENCE ON MANAGING PLANT NUTRITION, 1999, Barcelona. Proceedings... Barcelona: IFA, 1999.

MARSCHNER, H. Mineral nutrition of higher plants. 2 ed. New York: Acad. Press, 1995. 889 p. MAYNARD, D.N.; BARKER, A.V.; MINOTTI P.L.; PECK, N.H. Nitrate accumulation in vegetables. Advances in Agronomy, New York, v.28, p.71-118, 1976.

PEREIRA, N.N.C.; FERNANDES, M.S.; ALMEIDA, D.L. Adubação nitrogenada na cultura da alface: fontes de $\mathrm{N}$ e inibidos da nitrificação. Pesquisa Agropecuária brasileira, Brasília v.24, n.6, p.647-654, 1989.
RUSCHEL, J., CAMARGO, Q.A., ANTI, G.R. Concentração de nitrato em duas cultivares de alface cultivadas em hidroponia, em função de doses de nitrogênio e de potássio. 1998. In: FERTBIO 1998, Caxambu, 1998. Anais... Caxambu, SBCS, 1998. CD-Rom.

VAN DER BOON, J.; STEENHUIZEN, J.W.; STEINGRÖVER, E.G. Growth and nitrate concentration of lettuce as affected by nitrogen and chloride concentration, $\mathrm{NH}_{4}^{+} / \mathrm{NO}_{3}{ }^{-}$ratio and temperature of the recirculating nutrient solution. Journal of Horticultural Science, Kent, v.65, n.3, p.309-321, 1990.

WEATHERBURN, M.W. Phenol-hypochlorite reaction for determination of ammonia. Analytical Chemistry, v.39, n.8, p.971-974, 1967.

WRIGHT, M.J.; DAVISON, K.L. Nitrate accumulation in crops and nitrate poisoning in animals. Advances in Agronomy, New York, v.16, p.197-274, 1964.

YEMM, E.W. ;WILLIS, A.J. The estimation of carbohydrates in plant extracts by anthrone. Biochem. J., v.57, p.508-514, 1954.

YEMM, E.W.; COCKING, E.C. The determination of amino-acids with ninhydrin. Analyst, v.80, p.209-213, 1955. 